\title{
The effect of openings on stress distribution in glass beams - Dependence on a hole to beam's edge distance
}

\author{
Martin Lavko ${ }^{1, *}$, Vincent Kvočák ${ }^{2}$, and Zdeněk Sokol ${ }^{2}$ \\ ${ }^{1}$ Technical University of Kosice, Faculty of Civil Engineering, Department of Steel and Timber \\ Structures, Slovakia \\ ${ }^{2}$ Czech Technical University in Prague, Faculty of Civil Engineering, Department of Steel and Timber \\ Structures, Czech Republic
}

\begin{abstract}
The paper defines the behaviour of simply supported monolithic glass beam consisting of only one layer glass pane with discontinuities created by four holes positioned symmetrically on the beam. Similar glass panes can be found in real constructions where they act as a beam supporting glazing, roofs or decks of nowadays very popular transparent pedestrian bridges. The main aim of this paper is to provide both experimental and numerical analysis of stress distribution alongside the beam with a focus on areas where peak stresses may occur. The areas of interest are specifically speaking around openings, around supports and in the areas where the forces are introduced to the beam. As Eurocode standards for structural glass are still in the process of codifying and most of the nowadays literature only provides suggested axial distance of holes and hole to pane edge distance based on the thickness of the glass pane. This paper will provide the future designers of glass load-bearing structures with a closer look at stress distribution around the mentioned area. It was essential to do parametric study in software using FEM to investigate as much as possible axial distances of openings without a significant increment in the total cost of the experiment.
\end{abstract}

\section{Introduction}

The widespread of using glass is brought by modern architecture and progressive architects who are not afraid of designing subtitle and transparent structures. Glass as a load-bearing material has an irreplaceable place in Building construction business of 21 st century, where it is used for glazing of façades, bridges, ceilings, and staircases [4]. When used as a loadbearing structure it not only transfers self-weight to other load-bearing structures but actively transfers loads like wind, snow or forces acting on a structure during the fire, to foundations and then to soil [1].

\footnotetext{
* Corresponding author: martin.lavko@tuke.sk
} 


\section{Influence of discontinuities}

Very common form of connecting the glass components to each other or to a different primary load-bearing structures made of materials like steel, concrete or timber is bolted connection, for which it is necessary to drill holes into glass plies. Those openings negatively influence the load-bearing capacity of the glass component. Nowadays very popular all-glass structures with the glazing (secondary load-bearing structure) joined to the glass beams with holes as a primary load-bearing structure, are designed in dozens all over the world, but there is not a universal guide for determining the hole to edge distance according to the way of loading.

\subsection{Drilling}

Making of holes is done in the diamond drilling process by local grinding [1]. Drilling is done from both sides at the same time and the maximum diameter of opening with normal tools is around 70 millimeters. With special ones, it might be up to $150 \mathrm{~mm}$. Universally accepted rules for defining the distance between the hole and the edge and between the holes themselves are still not set [1]. The recommended ones are shown in the figure below.

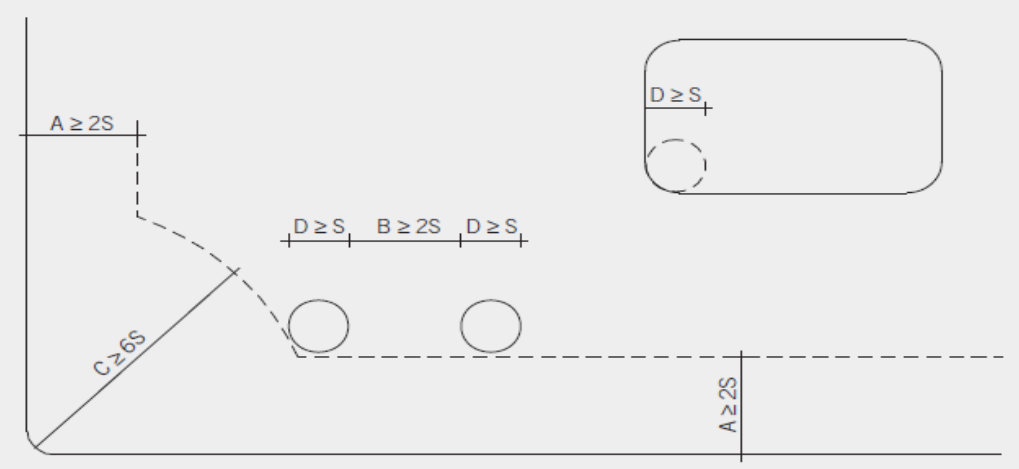
A Edge distance
B Distance between holes (hole edge to hole edge)
C Distance to corner
Hole diameter
Glass thickness

Fig. 1. Recommended positioning of holes (conservative approach intended for guidance only) [1].

\section{Experimental analysis}

The experimental analysis consists of testing 3 specimens, which were tested in the laboratory of CTU in Prague. All specimens numbered N01-N03 were fabricated out of the heatstrengthened glass of thickness $12 \mathrm{~mm}$ with the suggested minimal characteristic strength of glass $70 \mathrm{MPa}$. The geometry of glass beams is shown in the figure below. 

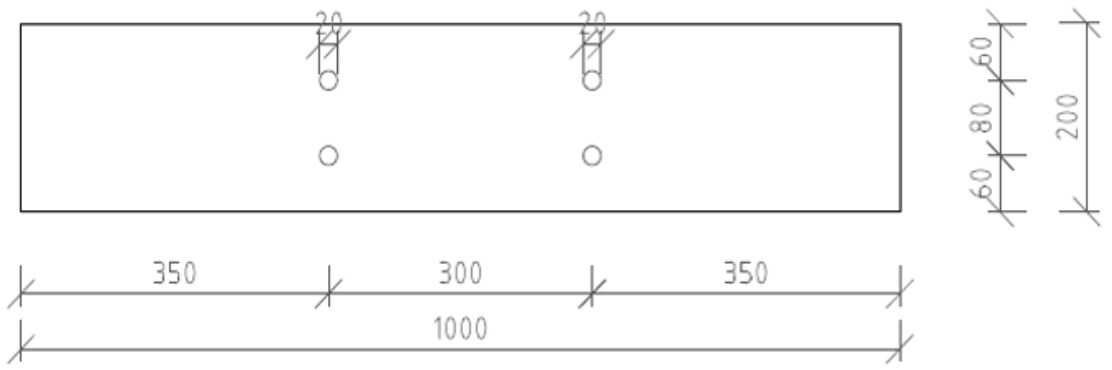

Fig. 2. Glass beams used for experimental analysis (distances in $\mathrm{mm}$ ).

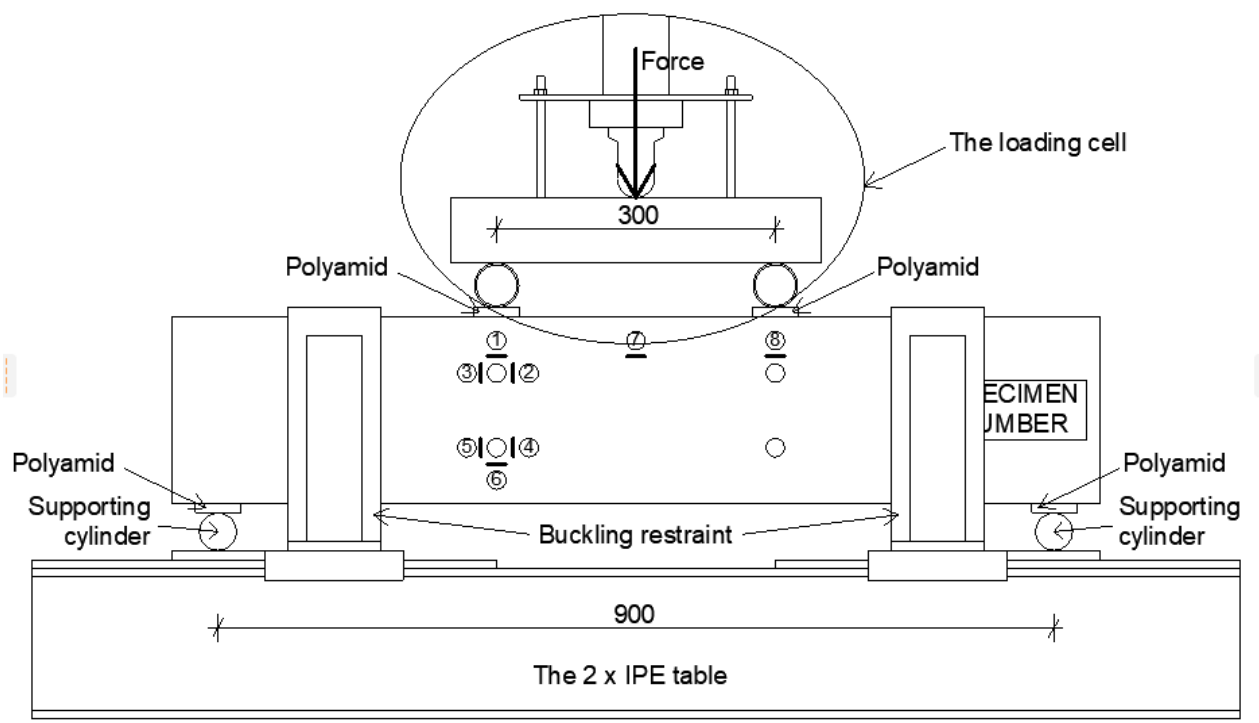

Fig. 3. A detailed description of the loading assembly with the specimen.

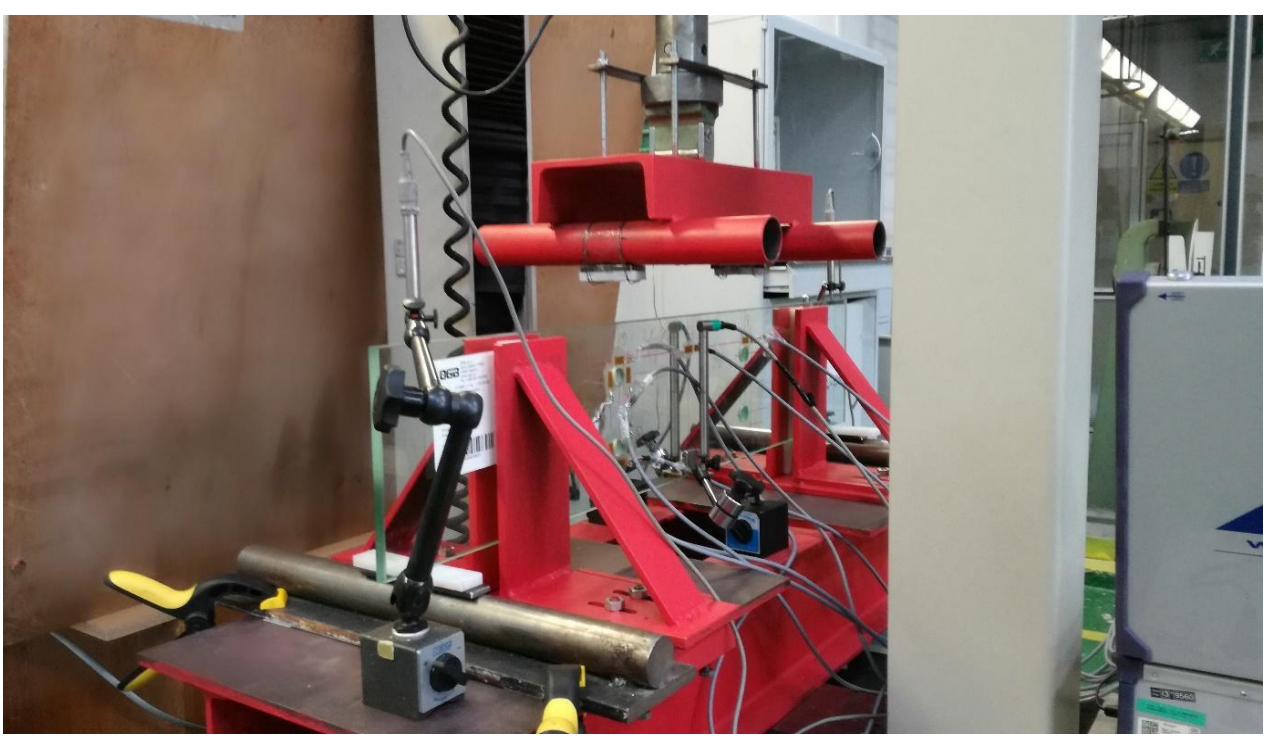

Fig. 4. The loading assembly with specimen N01 ready for loading. 
A four-point flexural bending test was used, which leads to a constant moment in between the forces. The consequence of the moment distribution as described is that the crack will appear in the weakest point of the specimen. Then, from the crack pattern of the broken specimen, it is obvious in which point stress exceeded the load-bearing capacity of the specimen the first. The tests were running until the failure of a structure.

The tested specimen was supported by 2 steel cylinders and between the steel component and the beam to avoid peak stresses in the contact area. Four rod extensometers were used to measure the vertical deflection. Two of them were placed on the top edge of the beam above the supports and the other two were measured deflection in the middle of each specimen. As there were plastic washers from polyamide inserted between the steel supporting cylinder and the glass beam, the deformation of the polyamide showed as significant. To obtain the real deflection of the beam in the middle of its span, vertical deformation measured in the centre must be subtracted by the vertical deformation measured by extensometers placed in the points above the supports. The axial distance between supports was set to $900 \mathrm{~mm}$ and two forces were introduced to the beam by the loading cell made from steel components. Again, polyamide stripes were places between steel and glass.

\subsection{Experimental analysis - results}

The ultimate limit state was reached for each specimen. As it is characteristic for glass, the collapse of the structure was immediate (brittle failure). Due to the manufacturing process, differences in stiffness of each specimen were recorded. A comparison of values obtained from the tests and the average value of force and deflection reached at breakage is shown in the table below. The maximum vertical deflection shown in the table is the clear vertical deflection of the glass beam as the deformation of polyamide stripes was deducted.

Table 1. Maximum force and deflection reached for each specimen.

\begin{tabular}{|l|c|c|c|}
\hline & Max. force & Max. deflection & Stiffness \\
\hline & {$[\mathrm{kN}]$} & {$[\mathrm{mm}]$} & {$[\mathrm{kN} / \mathrm{mm}]$} \\
\hline N01 & 39.06 & 1.259 & 31.017 \\
\hline $\mathbf{N 0 2}$ & 32.07 & 1.081 & 29.677 \\
\hline $\mathbf{N 0 3}$ & 36.38 & 1.146 & 31.746 \\
\hline Avarage & 35.84 & 1.162 & 30.813 \\
\hline
\end{tabular}

It was noticeable from the crack pattern of specimens N02 (Fig. 4.) and N03, that the initial crack occurred at the edge of the low left opening, which signals that during the tests maximum stresses occurred at the described point. 


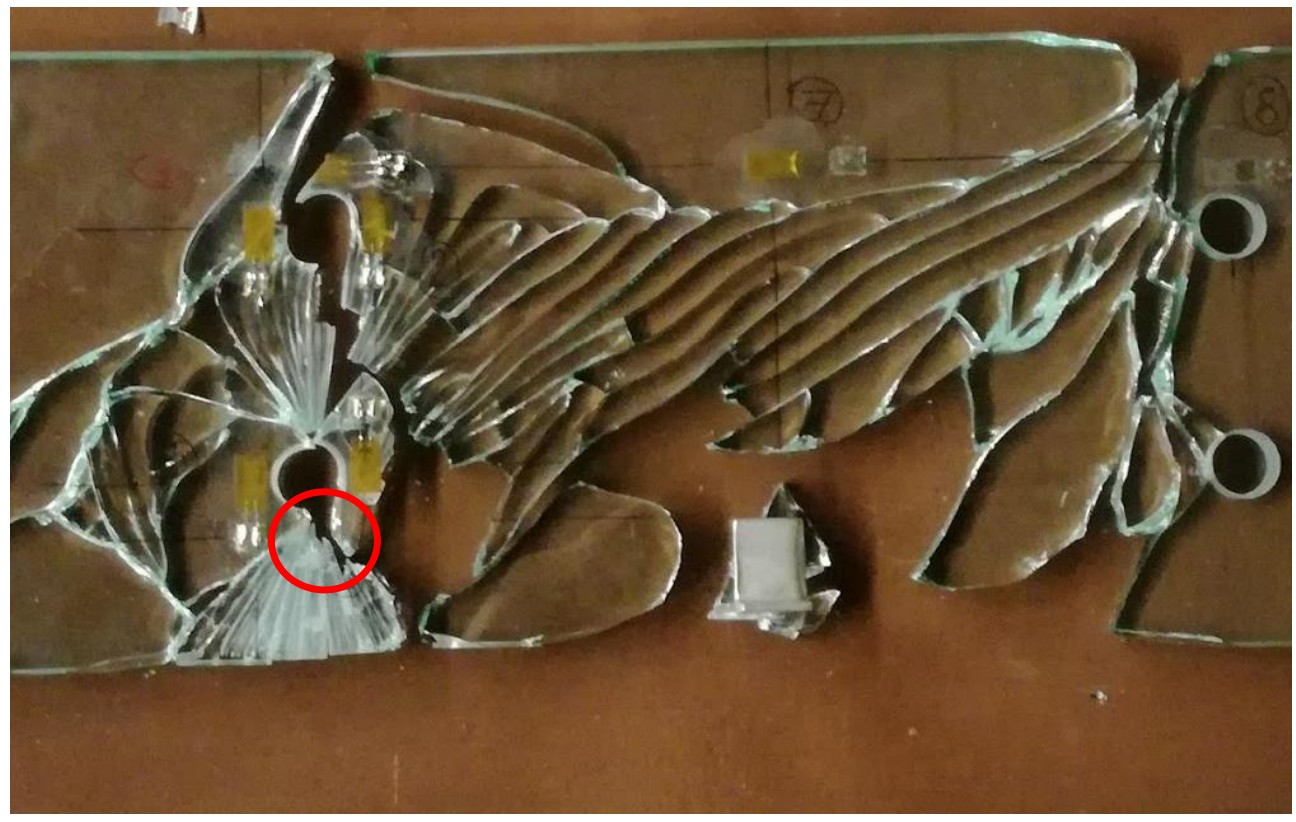

Fig. 5. Point of the initial crack (marked red).

\section{Numerical analysis}

The numerical model was created in ANSYS Workbench 19.0 (student license) software. Due to computing time savings, the symmetry of tested beams was used and only half of the specimen was modelled. The model was loaded by the average force obtained from the experimental analysis and so $F=17.92 \mathrm{kN}$ while the maximum vertical deflection calculated in ANSYS was $1.155 \mathrm{~mm}$. The average stiffness of all 3 tested specimens is $K=31.041 \mathrm{kN} / \mathrm{mm}$ which corresponds with the one obtained from software $K=30.813$ $\mathrm{kN} / \mathrm{mm}$. Also, the maximum stress in the model was recorded in the point where the initial crack in the beams was observed.

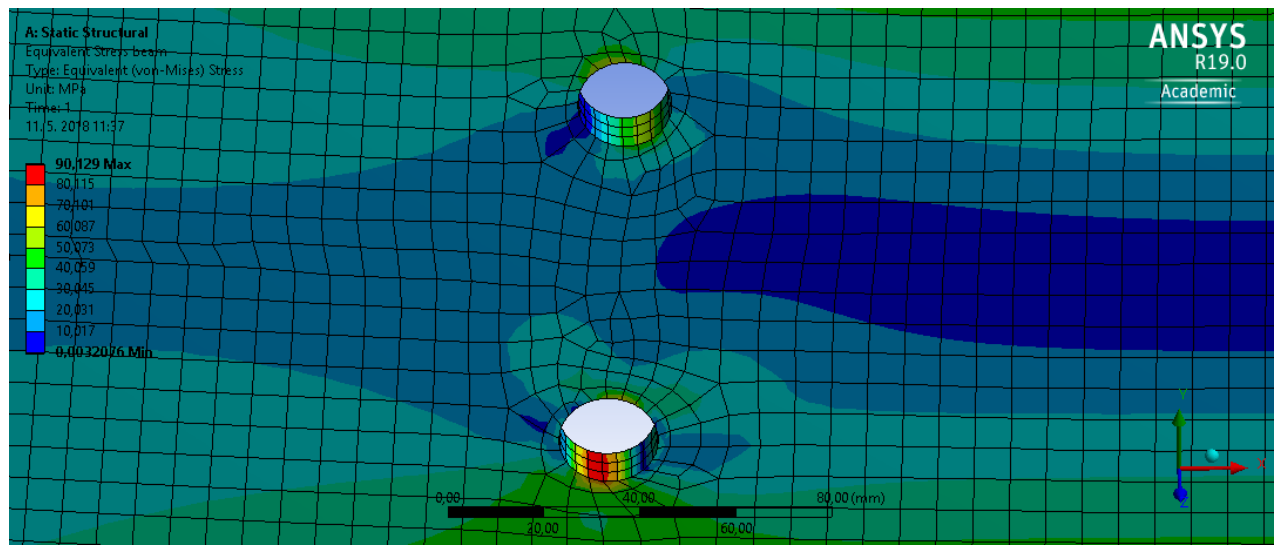

Fig. 6. Maximum stress at the edge of the lower opening. 


\subsection{Parametric study}

The validated numerical model was used in the parametric study The distance between the holes was symmetrically changed with respect to the horizontal axis of symmetry of the beam. The values of the axial vertical distance between the holes, as well as the distance between the edge of the hole and the longer edge of the beam used for the parametric study, are shown in Table 2. In the mentioned table the axial distance is marked by shortcut "a" and the edge to edge distance is represented by " $b$ ". Stresses shown in the table were measured at the bottom edge of the lower opening. Although presented stresses for the axial distance 30,40 , and $60 \mathrm{~mm}$ were not the maximum stresses reached on the beam. The higher stress was recorded around the supports. Starting with the axial distance $80 \mathrm{~mm}$, the maximum stress in the beam occurred at the bottom of the edge of the lower opening.

Table 2. Input and output parametric quantities for variable position of opening.

\begin{tabular}{|l|c|c|c|c|c|c|c|c|c|c|c|}
\hline $\mathbf{a}[\mathbf{m m}]$ & 30 & 40 & 60 & 80 & 100 & 120 & 140 & 150 & 155 & 160 & 170 \\
\hline $\mathbf{b}[\mathbf{m m}]$ & 75 & 70 & 60 & 50 & 40 & 30 & 20 & 15 & 12,5 & 10 & 5 \\
\hline $\begin{array}{l}\text { Max } \boldsymbol{\sigma} \\
\text { [Mpa] }\end{array}$ & 48.24 & 52.46 & 69.33 & 90.13 & 103.04 & 125.79 & 159.14 & 168.07 & 191.84 & 191.37 & 284.67 \\
\hline
\end{tabular}

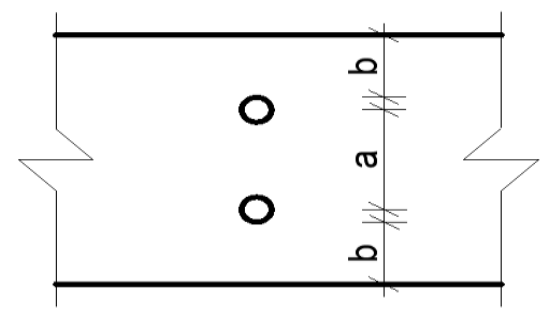

Fig. 7. Distances "a" and "b".

In bending caused by a four-point flexural test the bending stress equals zero at the beam's neutral axis, which is identical with the horizontal axis of symmetry of the presented beam. The bending stress increases linearly away from the neutral axis to the maximum values at the top and bottom of the beam. Thus, linear stress increment was expected for this parametric study. But as shown in Fig. 6, a significant increase that interrupts the linear character of stress increment develops after reaching the axial distance of holes of $150 \mathrm{~mm}(15 \mathrm{~mm}$ from the edge of the hole to the edge of the beam).

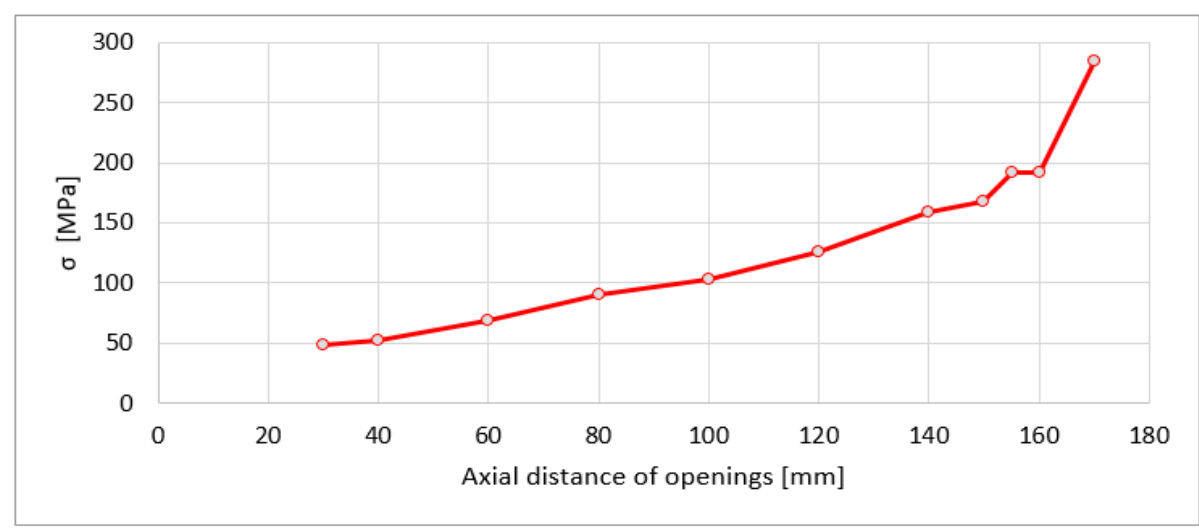

Fig. 8. Correlation between the axial distance between the openings and maximum stress at the edge of the hole. 


\section{Conclusion}

Three specimens made out of a heat-strengthened glass which were tested in the four-point flexural test. When the strength of specimens was exceeded, a brittle failure characteristic for glass structures appeared immediately. Then, the crack pattern and shards were studied carefully and the bottom edge of the lower opening was marked as the point of initial crack which spread promptly across the whole beam.

The parametric study provided the data which were compared to suggested distances mentioned in previous chapters. In the parametric study, the axial distance between the openings was changing while the diameter remained unchanged, the change of stiffness was exponential. It was decreasing as the axial distance of openings was increasing, and no changes in the glass mass were provided. A significant decrease in stiffness was recorded as the axial distance reaches $140 \mathrm{~mm}$. At this point, the edge of the opening was $20 \mathrm{~mm}$ far from the edge of the beam, which is also the diameter of the holes in the tested beams. Suggested edge distance for designers is $\mathrm{A} \geq 2 \mathrm{~S}$, where $\mathrm{A}$ is the hole edge to beam edge distance and $\mathrm{S}$ is the thickness of a glass pane, but dramatic changes in stiffness occurred in $\mathrm{A}=\mathrm{S}$ distance. Although, the stress was changing almost linearly from the axial distance of $30 \mathrm{~mm}$ to 150 $\mathrm{mm}$, which is $15 \mathrm{~mm}$ from edge to edge.

The presented paper was supported by the project: VEGA 1/0188/16 "Static and Fatigue Resistance of Joints and Members of Steel and Composite Structures" and VEGA 1/0374/19 of the Scientific Grant Agency of the Ministry of Education, science research and sport of the Slovak Republic and the Slovak Academy of Sciences.

\section{References}

1. J. Wurm, Glass structures: design and construction of self-supporting skins (2007)

2. Ch. O'Regan and col., Structural use of glass in buildings (Second edition) (2015)

3. F. Wald, J. Macháček and M. Eliášová, et al. Novinky v navrhování ocelových a dřvěných konstrukci se zaměrením na skleněné konstrukce

4. M. Eliášová, Lectures of Glass structures

5. R. Vencl, Analýza chování nepředepnutých šroubovaných spojů konstrukcí ze skla (2011).

6. M. Haldimann, A. Luible and M. Overend, Structural Use of Glass (2008)

7. B. Weller and K. Härth, Experimental Research on Glass-Polycarbonate Beams, Challenging Glass 2 - Conference on Architectural and Structural Applications of Glass

8. B. Weller, A. Meier and T. Weimar, Challenging Glass 2 - Conference on Architectural and Structural Applications of Glass

9. M. Feldmann, R. Kasper and col. Guidance for European structural design of glass components: support to the implementation, harmonization and further development of the Eurocodes 